\title{
Hysteresis Phenomena on Platinum and Palladium-based Diesel Oxidation Catalysts (DOCs)
}

\author{
H. Dubbe ${ }^{1} \cdot$ F. Bühner ${ }^{1}$ G. Eigenberger ${ }^{1} \cdot$ U. Nieken $^{1}$
}

Received: 1 September 2015 / Revised: 10 December 2015 / Accepted: 15 March 2016 / Published online: 8 April 2016

(c) Springer International Publishing Switzerland 2016

\begin{abstract}
The diesel oxidation catalyst (DOC) plays a key role in diesel exhaust treatment systems. Typical noble metals used as active components are platinum $(\mathrm{Pt})$ and palladium (Pd). During lightoff/lightout experiments, the catalyst reactivity during heating is in some cases different from the reactivity during cooling in the same reaction mixture. These so called hysteresis phenomena have repeatedly been reported for $\mathrm{CO}, \mathrm{NO}$, and $\mathrm{HC}$ conversion and are mostly attributed to noble metal oxidation and/or surface coverage effects. Hauff et al. have developed a kinetic model that is able to account for the hysteresis effects observed in NO conversion on Pt-only catalysts due to noble metal oxidation. The model was only validated for a limited range of NO concentrations and temperatures. In this follow-up, further experiments on Pt-only as well as on Pd-only catalysts will be presented for additional feed compositions. General transferability of the Pt-only model to Pd-only catalysts for NO-only is demonstrated. By addition of $\mathrm{CO}$ and propene to the feed, additional hysteresis phenomena are observed and will be discussed. On Pd-only, results indicate that under lean exhaust conditions, the noble metal can only be slightly reduced by $\mathrm{CO}$. Interestingly, with a mix of $\mathrm{CO}$ and $\mathrm{NO}$ no reactivation is observed whereas the combination of $\mathrm{CO}$, $\mathrm{NO}$, and propene again shows reducing tendency. Based on these informations, a possible modeling approach will be proposed.
\end{abstract}

H. Dubbe

hendrik.dubbe@icvt.uni-stuttgart.de

1 Institute of Chemical Process Engineering, University of Stuttgart, Böblinger Straße 78, 70199, Stuttgart, Germany
Keywords NO oxidation · Hysteresis · Deactivation · Reactivation $\cdot$ Platinum $\cdot$ Palladium

\section{Introduction}

The diesel oxidation catalyst (DOC) is a key element in typical diesel exhaust treatment systems. Typical catalysts are platinum $(\mathrm{Pt})$, palladium $(\mathrm{Pd})$, or a combination of both (Pt/Pd, e.g., alloyed, multilayered). During lightoff/lightout experiments, hysteresis phenomena of $\mathrm{NO}, \mathrm{CO}$, and $\mathrm{HC}$ conversion have repeatedly been reported in literature and attributed to noble metal oxidation $[1,2]$ or to surface coverage effects [3].

Hauff et al. developed a global kinetic model that is able to account for hysteresis effects observed in NO conversion on Pt-only catalysts due to noble metal oxidation, neglecting surface coverage phenomena [4]. However, the model was only validated for a limited range of $\mathrm{NO}$ concentrations and temperatures. In this follow-up, further experiments with different NO concentrations will be presented. Suitable model modifications are introduced to fit the experimental results.

By addition of $\mathrm{CO}$ and propene to the feed, further hysteresis phenomena are observed which could either be attributed to surface coverage effects or to noble metal oxidation. A phenomenological model will be proposed in which NO hysteresis phenomena are regarded as solely dependent on the catalyst oxidation state.

\section{Experimental Setup}

Near-series monometallic model DOCs have been provided by Umicore AG \& Co.KG (Me- $\gamma-\mathrm{Al}_{2} \mathrm{O}_{3}, 400 \mathrm{cpsi}, 6.5 \mathrm{mil}$, 
Fig. 1 Schematic of the isothermal flat-bed reactor

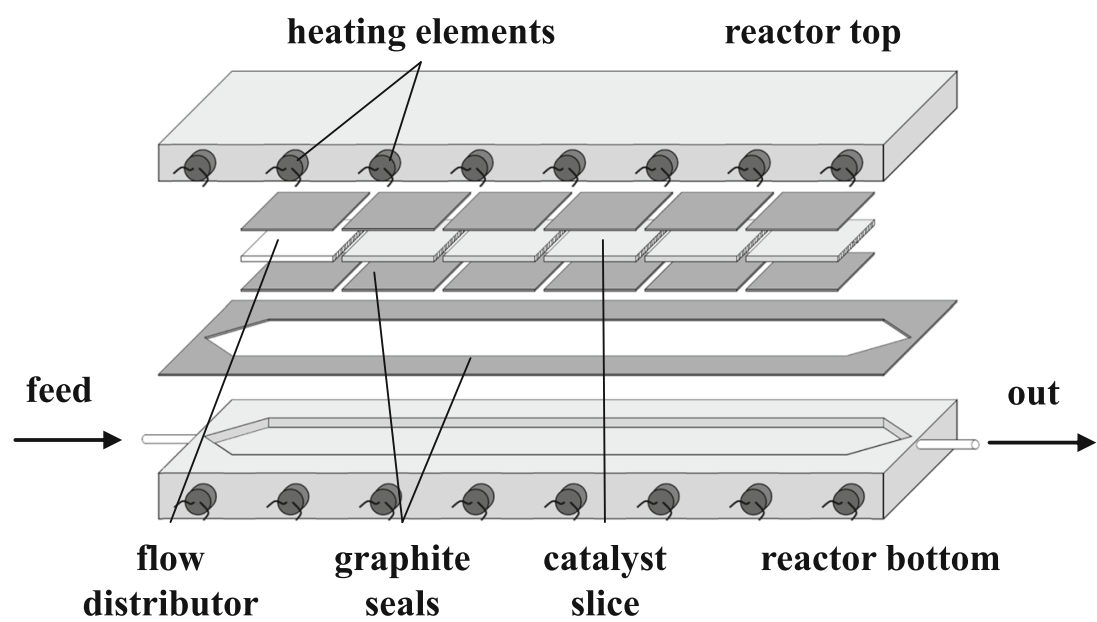

$\left.80 \mathrm{~g}_{M e} / \mathrm{ft}_{c a t}^{3}\right)$. After hydrothermal degreening ( $24 \mathrm{~h}$ at 550 ${ }^{\circ} \mathrm{C}, 10 \% \mathrm{H}_{2} \mathrm{O}$ in air), thin slices $(30 \times 37 \times 1.4 \mathrm{~mm})$ of the catalyst have been tested in a temperature-controlled metallic flat-bed reactor [6] (Fig. 1) under reproducibly isothermal conditions. After reducing pretreatment, temperature ramp experiments were conducted according to Fig. 2.

A permanent feed of $5 \% \mathrm{H}_{2} \mathrm{O}, 7 \% \mathrm{CO}_{2}$, and $5 \%$ $\mathrm{O}_{2}$ in $\mathrm{N}_{2}$ was used during all experiments at a constant space velocity of $40,000 \mathrm{~h}^{-1}$. Different concentrations of $\mathrm{CO}, \mathrm{NO}$, and $\mathrm{C}_{3} \mathrm{H}_{6}$ are added to the feed. Experiments with one, two, and all three noxious substances have been conducted on both Pt and Pd catalysts to illuminate the individual conversion behavior as well as the mutual inhibition effects.

At the beginning of each experiment, the catalyst is pretreated under reducing atmosphere $\left(1 \mathrm{~h}\right.$ at $350{ }^{\circ} \mathrm{C}, 3 \%$ $\mathrm{H}_{2}, \mathrm{~N}_{2}$ balance). After cooling down to start temperature $\left(60^{\circ} \mathrm{C}\right)$, the feed is adjusted and successive temperature ramps with $\pm 3 \mathrm{~K} / \mathrm{min}$ are performed until the cyclic stationary state is reached. This is the case after a maximum of two up/down cycles. Only the first two up-down-cycles will be presented in the following. Concentrations are measured using a MultiGas ${ }^{\mathrm{TM}} 2030$ FTIR Continuous Gas Analyzer from MKS Instruments.

\section{Results}

At first, the NO-oxidation on the Pt-only catalyst will be reinvestigated. Then, the transferability of the existing noble metal oxidation model to Pd-only catalyst will be discussed. Afterwards, suitable model extensions of the existing $\mathrm{Me} / \mathrm{MeO}$ model will be proposed to account for $\mathrm{CO}$ and $\mathrm{C}_{3} \mathrm{H}_{6}$ influence.

\subsection{NO-Oxidation}

On Pt, additional experiments with 250, 500, and 1000 ppm NO were conducted. Figure 3 shows the resulting $\mathrm{NO}$ conversion traces to $\mathrm{NO}_{2}$ during lightoff and lightout. An inverse hysteresis as entitled by Hauptmann [1] can be seen in all cases. With increasing concentration of NO, the overall conversion decreases.
Fig. 2 Temperature profile during initial reducing pretreatment with $\mathrm{H}_{2}$ and $\mathrm{N}_{2}$ and subsequent lightoff/lightout

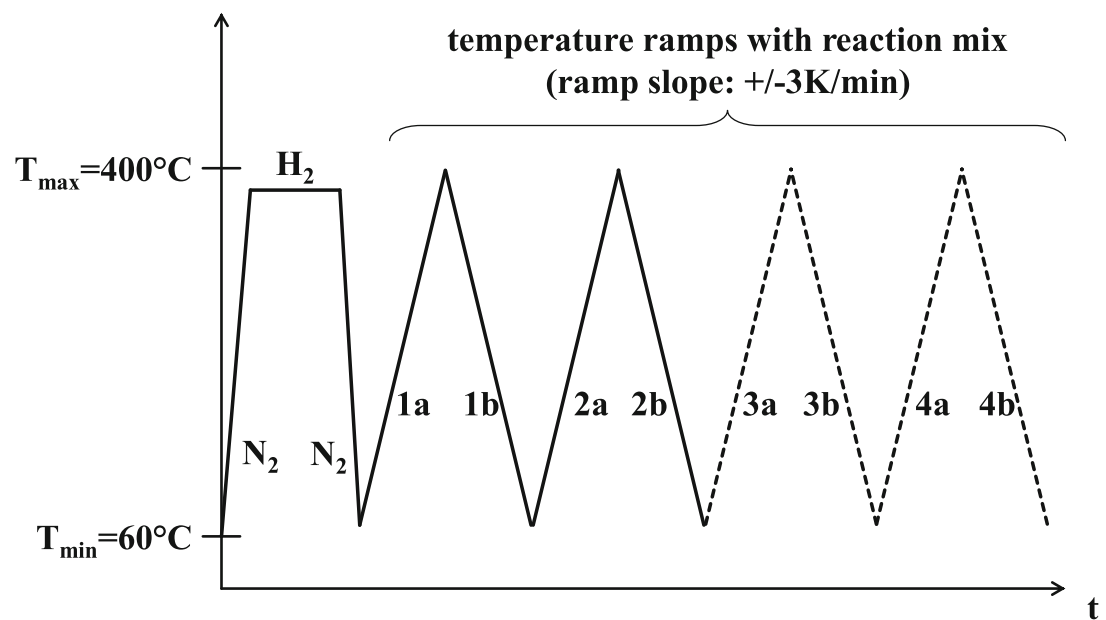



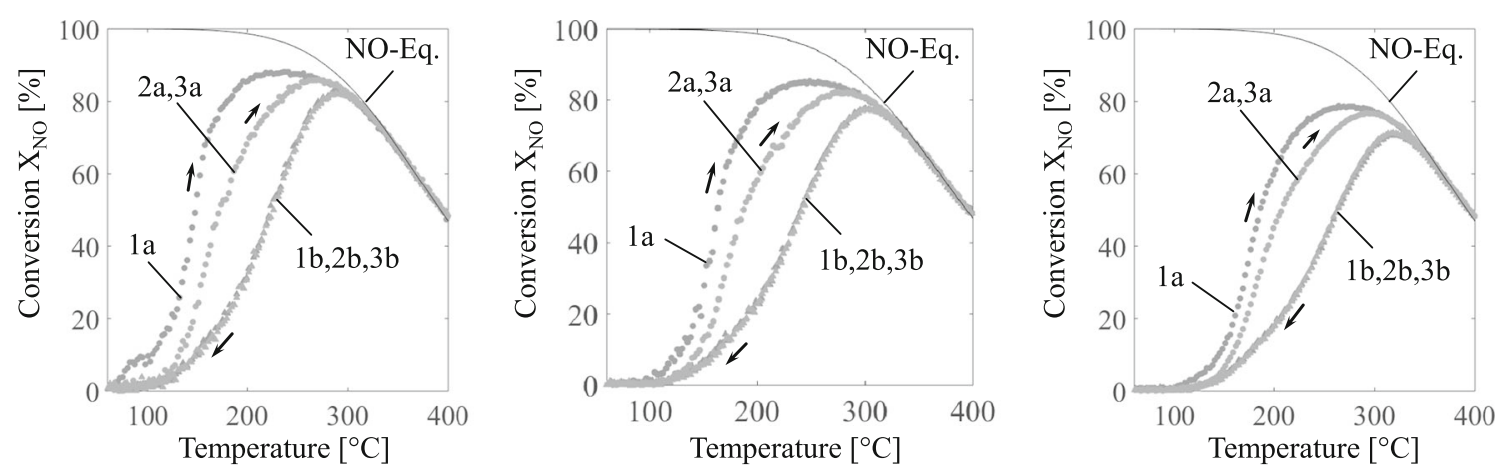

Fig. 3 NO-only lightoff/lightout experiments on Pt-catalyst with 250 ppm (left), 500 ppm (center), and 1000 ppm (right) NO

At the beginning of the first ramp-up (1a), the Pt catalyst is fully reduced, implying highest activity. During the heat-up phase, the catalyst is oxidized. At temperatures above $350{ }^{\circ} \mathrm{C}$, thermal decomposition of $\mathrm{PtO}$ starts and the conversion becomes limited by the $\mathrm{NO} / \mathrm{NO}_{2}$ equilibrium. During cooling down (1b), the catalyst is partially reduced by NO, resulting in an increased NO conversion during subsequent heating (2a). Since the conversion during the second ramp-up (2a) is lower than during the first ramp-up (1a), the previous reduction has obviously not been complete but only partial. Hauff et al. proposed a global kinetic approach that accounts for de- and reactivation by noble metal oxidation and reduction [4]. It is assumed that two different reaction rates exist on either $\mathrm{Pt}\left(r_{\mathrm{NO}, \mathrm{O}_{2}}^{\mathrm{Pt}}\right)$ or $\mathrm{PtO}\left(r_{\mathrm{NO}, \mathrm{O}_{2}}^{\mathrm{PtO}}\right)$ that are both described by Langmuir-Hinshelwood-HougenWatson (LHHW) kinetics:

$$
\begin{aligned}
r_{\mathrm{NO}, \mathrm{O}_{2}}^{\mathrm{Pt} / \mathrm{PtO}}= & \frac{k^{\mathrm{Pt} / \mathrm{PtO}}(\mathrm{T}) \cdot y_{\mathrm{NO}} \cdot y_{\mathrm{O}_{2}}}{\left(I_{\mathrm{NO}, \mathrm{O}_{2}}^{\mathrm{Pt} / \mathrm{PtO}}\right)^{2}} \\
& \cdot\left(1-\frac{y_{\mathrm{NO}_{2}}}{y_{\mathrm{NO}} \cdot \sqrt{y_{\mathrm{O}_{2}}} \cdot K_{\mathrm{NO}, \mathrm{O}_{2}}}\right) \\
I_{\mathrm{NO}, \mathrm{O}_{2}}^{\mathrm{Pt} / \mathrm{PtO}}= & 1+K_{\text {inh, NO}}^{\mathrm{Pt} / \mathrm{PtO} O} \cdot y_{\mathrm{NO}}+K_{\text {inh }, \mathrm{NO}_{2}}^{\mathrm{Pt} / \mathrm{PtO}} \cdot y_{N O_{2}}
\end{aligned}
$$

$\mathrm{K}_{\mathrm{NO}, \mathrm{O}_{2}}$ is the equilibrium constant of the NO oxidation. The rate constant $k(T)$ and the inhibition constants
$\mathrm{K}_{i n h, \mathrm{NO}}^{\mathrm{Pt} / \mathrm{PtO}}$ and $\mathrm{K}_{i n h, \mathrm{NO}_{2}}^{\mathrm{Pt} / \mathrm{PtO}}$ are temperature dependent according to Arrhenius:

$$
\begin{aligned}
& k^{P t / P t O}(T)=k_{0}^{P t / P t O} \cdot \exp \left[-\frac{E_{a}^{P t / P t O}}{R} \cdot\left(\frac{1}{T}-\frac{1}{T_{0}}\right)\right] \\
& K_{i n h, N O}^{P t / P t O}=K_{0, i n h, N O}^{P t / P t O} \cdot \exp \left[-\frac{E_{i, N O}^{P t / P t O}}{R} \cdot\left(\frac{1}{T}-\frac{1}{T_{0}}\right)\right] \\
& K_{i n h, \mathrm{NO}_{2}}^{\mathrm{Pt/P \textrm {O }}}=K_{0, \text { inh }, \mathrm{NO}_{2}}^{\mathrm{Pt/PtO}} \cdot \exp \left[-\frac{E_{i, \mathrm{NO} \mathrm{O}_{2}}^{\mathrm{Pt} / \mathrm{PtO}}}{R} \cdot\left(\frac{1}{T}-\frac{1}{T_{0}}\right)\right](5)
\end{aligned}
$$

In the Arrhenius term, $T$ is the absolute temperature and $T_{0}$ a suitable reference temperature. The rate on $\mathrm{Pt}$ is always higher than on PtO. In the following, $\Theta_{P t}$ describes the fraction of the reduced catalyst, where $\Theta_{P t}=1$ denotes a fully reduced catalyst and $\Theta_{P t}=0$ a completely oxidised one. The overall reaction rate $r_{\mathrm{NO}, \mathrm{O}_{2}}^{g e s}$ is then calculated by weighted interpolation of the rates for pure $\mathrm{Pt}$ and for pure PtO:

$r_{\mathrm{NO}, \mathrm{O}_{2}}^{\mathrm{ges}}=r_{\mathrm{NO}, \mathrm{O}_{2}}^{\mathrm{Pt}} \cdot \Theta_{\mathrm{Pt}}+r_{\mathrm{NO}, \mathrm{O}_{2}}^{\mathrm{PtO}} \cdot\left(1-\Theta_{\mathrm{Pt}}\right)$

The previous model [4] only accounts for Pt oxidation by $\mathrm{O}_{2}$ and $\mathrm{PtO}$ reduction by $\mathrm{NO}$ as follows:

$$
\begin{aligned}
\mathrm{Pt} & +\frac{1}{2} \mathrm{O}_{2} \\
\mathrm{NO}+\mathrm{PtO} & +\mathrm{PtO}
\end{aligned}
$$
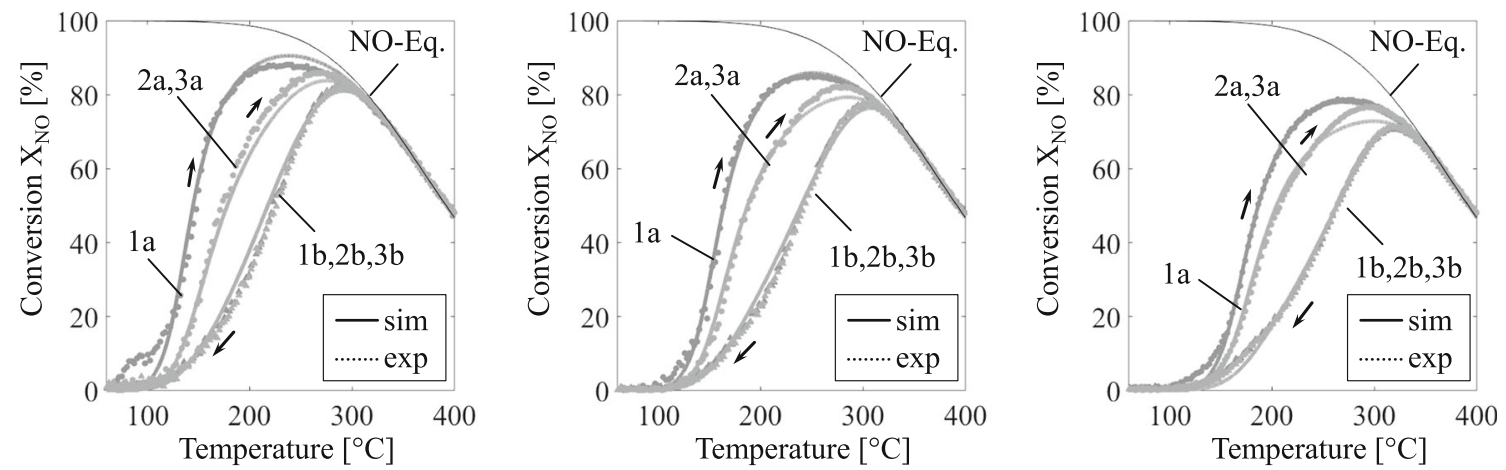

Fig. 4 NO-only simulation results on Pt-catalyst with 250 ppm (left), 500 ppm (center), and 1000 ppm (right) NO 
Table 1 Model parameters for NO-oxidation on the Pt- and Pd-only catalyst

\begin{tabular}{llllll}
\hline & \multicolumn{2}{l}{$\mathrm{Pt}$} & $\mathrm{PtO}$ & $\mathrm{Pd}$ & $\mathrm{PdO}$ \\
\hline$k_{0}$ & {$\left[\frac{\mathrm{mol}}{\mathrm{m}^{2}}\right]$} & $+6.17 \times 10^{+0}$ & $+4.80 \times 10^{+0}$ & $+1.59 \times 10^{+1}$ & $+1.25 \times 10^{-1}$ \\
$E_{a}$ & {$\left[\frac{\mathrm{kJ}}{\mathrm{mol}}\right]$} & $+2.61 \times 10^{+4}$ & $+1.76 \times 10^{+4}$ & $+3.84 \times 10^{+4}$ & $+4.27 \times 10^{+4}$ \\
$K_{0, \text { inh }, \mathrm{NO}}$ & {$[-]$} & $+2.11 \times 10^{+3}$ & $+8.00 \times 10^{+3}$ & $+1.60 \times 10^{+4}$ & $+2.78 \times 10^{+4}$ \\
$E_{i, \mathrm{NO}}$ & {$\left[\frac{\mathrm{kJ}}{\mathrm{mol}}\right]$} & $-2.63 \times 10^{+4}$ & $-4.46 \times 10^{+4}$ & $-2.94 \times 10^{+2}$ & $-1.66 \times 10^{+4}$ \\
$K_{0, i n h, N O_{2}}$ & {$[-]$} & $+4.00 \times 10^{+2}$ & $+6.30 \times 10^{+4}$ & - & - \\
$E_{i, \mathrm{NO} \mathrm{O}_{2}}$ & {$\left[\frac{\mathrm{kJ}}{\mathrm{mol}}\right]$} & $-2.06 \times 10^{+4}$ & $-5.26 \times 10^{+4}$ & - & - \\
\hline
\end{tabular}

The rates are written as:

$$
\begin{aligned}
r_{P t, O_{2}}= & k_{1} \cdot \exp \left[-\frac{E_{1}}{R} \cdot\left(\frac{1}{T}-\frac{1}{T_{0}}\right)\right] \\
& \cdot\left(\Theta_{P t} \cdot y_{O_{2}}-\frac{1}{K_{P t, O_{2}}} \cdot\left(1-\Theta_{P t}\right)\right) \\
r_{N O, P t O}= & k_{2} \cdot \exp \left[-\frac{E_{2}}{R} \cdot\left(\frac{1}{T}-\frac{1}{T_{0}}\right)\right] \\
& \cdot\left(1-\Theta_{P t}\right) \cdot y_{N O}
\end{aligned}
$$

$K_{P t, O_{2}}$ is the (fitted) equilibrium constant that accounts for thermal reduction of $\mathrm{PtO}$.

To fit the extended experimental results of Fig. 3, two modifications had to be applied to the above model. First, the NO influence on the PtO reduction rate (10) was lowered as the initial model overestimated the NO influence:

$r_{N O, P t O}=k_{2} \cdot \exp \left[-\frac{E_{2}}{R} \cdot\left(\frac{1}{T}-\frac{1}{T_{0}}\right)\right] \cdot\left(1-\Theta_{P t}\right) \cdot y_{N O}^{\mathbf{0 , 5}}$

Secondly, $\mathrm{PtO}$ reduction rate described by reaction (8) turned out to be far too strong for temperatures below $160{ }^{\circ} \mathrm{C}$, since a negative activation energy had been assumed in order to describe reactivation at low temperatures. As a more plausible assumption, we now also considered the back reaction in Eq. 8 which was previously neglected:

$\mathrm{NO}+\mathrm{PtO} \rightleftharpoons \mathrm{Pt}+\mathrm{NO}_{2}$

The complete reaction rate can then be described as follows:

$$
\begin{aligned}
& r_{N O, P t O}= k_{2} \cdot \exp \left[-\frac{E_{2}}{R} \cdot\left(\frac{1}{T}-\frac{1}{T_{0}}\right)\right] \\
& \cdot\left(\left(1-\Theta_{P t}\right) \cdot y_{N O}^{0,5}-\frac{1}{K_{P t O, N O}}\right. \\
&\left.\cdot \Theta_{P t} \cdot y_{N O_{2}}\right)
\end{aligned}
$$

Here, $\mathrm{K}_{P t O, N O}$ is the equilibrium constant of the reaction. It is calculated using data from NIST Chemistry WebBook [5].

It shall be mentioned that this back-reaction has already been considered in the original paper by Hauptmann et al. [1]. They showed that the NO light-off for different NO feed concentrations can be well predicted if this reaction is taken into account. However, Hauff et al. neglected the back reaction, because in their experiments, only very low $\mathrm{NO}_{2}$ concentrations occurred [4].

The question that arises in this context is whether the noble metal oxidation rate (7) by $\mathrm{O}_{2}$ can be omitted, if the oxidation by $\mathrm{NO}_{2}$ is considered in the system. Hauptmann et al. have already addressed this issue [1]: Although it is known that pure $\mathrm{NO}_{2}$ has a much higher thermodynamic oxidation potential than $\mathrm{O}_{2}$, in our experiments, all $\mathrm{NO}_{2}$ is only formed by oxidation of NO. This implies that the thermodynamic oxidation potential of $\mathrm{NO}_{2}$ in the resulting $\mathrm{NO} / \mathrm{NO}_{2}$ gas mixture can never exceed the oxidation potential of $\mathrm{O}_{2}$. Therefore, both rates need to be considered in order to adequately describe the catalyst behavior.

Due to isothermal reaction conditions, the reactor system was modeled only with mass balances, extended by one additional balance for the platinum fraction $\Theta_{P t}$ [4].

Simulation results of the modified model are presented in Fig. 4. It can be seen that good agreement between experimental and simulation results can be achieved. The used parameters are listed in Tables 1 and 2 .

Furthermore, in Fig. 5, the simulation results of the platinum fraction $\Theta_{P t}$ are plotted over the temperature for the different feed compositions. In each case, one can observe the thermal decay of $\mathrm{PtO}$ at high temperatures and its reduction by $\mathrm{NO}$ at low temperatures. It is also shown that the reactivation of $\mathrm{Pt}$ becomes stronger with an increasing NO concentration in the feed. Based on the structure of the model, this is to be expected.

In the next step, the transferability of the noble metal oxidation model to $\mathrm{Pd}-$ only catalysts will be considered. The results of two subsequent lightoff/lightout cycles directly after reducing pretreatment with 500 ppm NO in the feed are shown in Fig. 6 (left). Obviously, NO conversion on Pd

Table 2 Model parameters for noble metal oxidation and reduction on the Pt- and Pd-only catalyst

\begin{tabular}{llll}
\hline & & Pt & Pd \\
\hline$k_{1}$ & {$\left[\frac{\mathrm{mol}}{\mathrm{m}^{2} \mathrm{~s}}\right]$} & $+3.03 \times 10^{-7}$ & $+2.04 \times 10^{-6}$ \\
$E_{1}$ & {$\left[\frac{\mathrm{kJ}}{\mathrm{mol}}\right]$} & $+3.93 \times 10^{+4}$ & $+3.17 \times 10^{+4}$ \\
$k_{2}$ & {$\left[\frac{\mathrm{mol}}{\mathrm{m}^{2} \mathrm{~s}}\right]$} & $+3.88 \times 10^{-6}$ & - \\
$E_{2}$ & {$\left[\frac{\mathrm{kJ}}{\mathrm{mol}}\right]$} & $+1.00 \times 10^{-3}$ & - \\
\hline
\end{tabular}



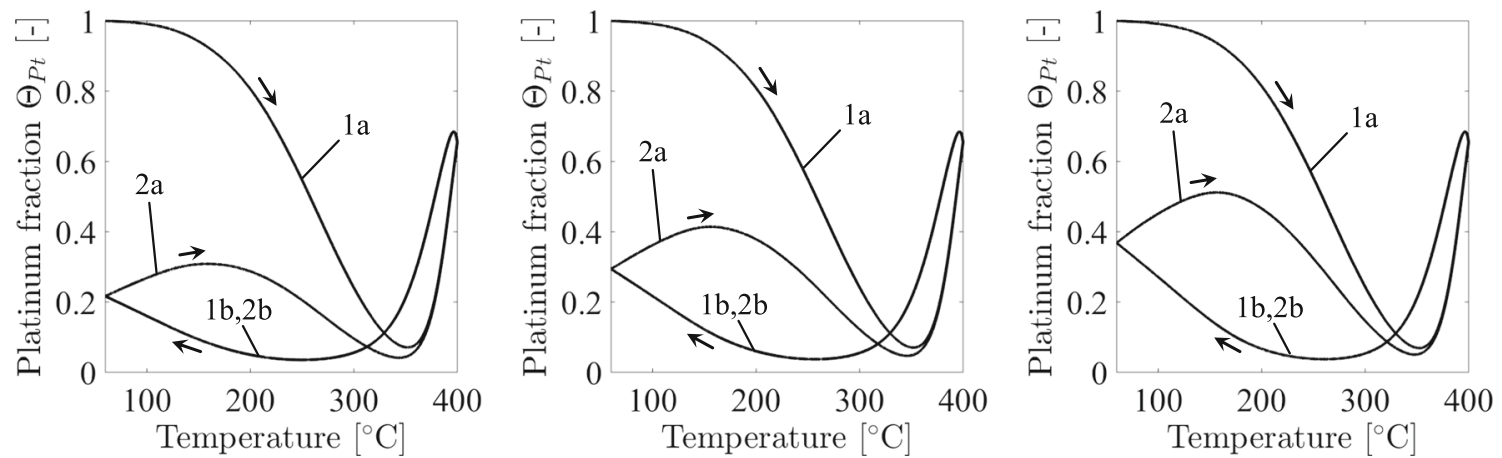

Fig. 5 Simulation results of the noble metal fraction $\Theta_{P t}$ on the Pt-catalyst with $250 \mathrm{ppm}$ (left), $500 \mathrm{ppm}$ (center), and $1000 \mathrm{ppm}$ (right) NO

is significantly lower than on Pt and no limitation by thermodynamic equilibrium is observed at temperatures up to $400{ }^{\circ} \mathrm{C}$. During first ramp-up, NO oxidation starts at about $150{ }^{\circ} \mathrm{C}$, but the conversion decreases subsequently before it slowly rises again. This indicates that after reducing pretreatment, Pd is more active than PdO. Furthermore, Fig. 6 (right) shows that at temperatures above $100{ }^{\circ} \mathrm{C}$ noble metal oxidation starts. Above $250{ }^{\circ} \mathrm{C}$, the catalyst is then almost completely oxidized which causes the conversion drop. Further heating then results in a rise of NO conversion solely on PdO due to the temperature dependency of the reaction. After the first lightoff/lightout cycle (1a, 1b), no reactivation of the catalyst is observed and the hysteresis vanishes. Therefore, no reactivation rate similar to Eq. 12 will be considered.

With this simplification, the noble metal oxidation model used for the Pt catalyst can be well calibrated to the Pd results as shown in Fig. 6 (left). The respective palladium fraction over temperature is shown in Fig. 6 (right). It can be seen that the Pd fraction drops from 100 to $0 \%$ during first lightoff (1a). No thermal reduction of PdO can be seen at high temperatures and no reduction by NO takes place at low temperatures. This means that the catalyst has reached a stable state after one lightoff.

The parameters used are also presented in Tables 1 and 2. The results support the assumption that pure (reduced) Pd is the more active component here compared to PdO.

It shall be noted that the activity of $\mathrm{Pd} / \mathrm{PdO}$ is controversely discussed in literature. Most of the studies focus on the $\mathrm{Pd} / \mathrm{PdO}$ activity for $\mathrm{CH}_{4}$ conversion, as this is currently a main application of $\mathrm{Pd}-$ only catalysts. Although it is widely assumed that $\mathrm{PdO}$ is the more active form [7, 8], results exist that favor Pd to be more active [9]. Especially for CO-only, higher activity for Pd compared to $\mathrm{PdO}$ has already been found [10]. This additionally supports the above assumption.

\section{2 $\mathrm{CO}$ and $\mathrm{HC}$ Influence}

Now the influence of $\mathrm{CO}$ and propene (as $\mathrm{HC}$ representative) is investigated when added to the feed. As the observed behavior severely differs between the platinum and the palladium catalyst, the results will be discussed separately starting with Pt.

\subsubsection{Platinum Catalyst}

The well known regular CO hysteresis on Pt due to surface coverage effects [3] vanishes when both $\mathrm{CO}$ and $\mathrm{NO}$ are present in the feed (see Fig. 7, left). Besides, contrary to Fig. 4 with pure NO feed, it can be seen that the catalyst can be fully reduced by $\mathrm{CO}$ and $\mathrm{NO}$, as the first and second ramp up (1a,2a) are practically identical. Thus, one additionally needs to account for the reduction of $\mathrm{PtO}$ by $\mathrm{CO}$. A formulation as global reaction step is proposed here:

$\mathrm{CO}+\mathrm{PtO} \rightarrow \mathrm{CO}_{2}+\mathrm{Pt}$
Fig. 6 NO-only results on Pd-catalyst with 500 ppm NO; experiment only (left); NO conversion (left) and fraction of pure Pd over temperature (right)
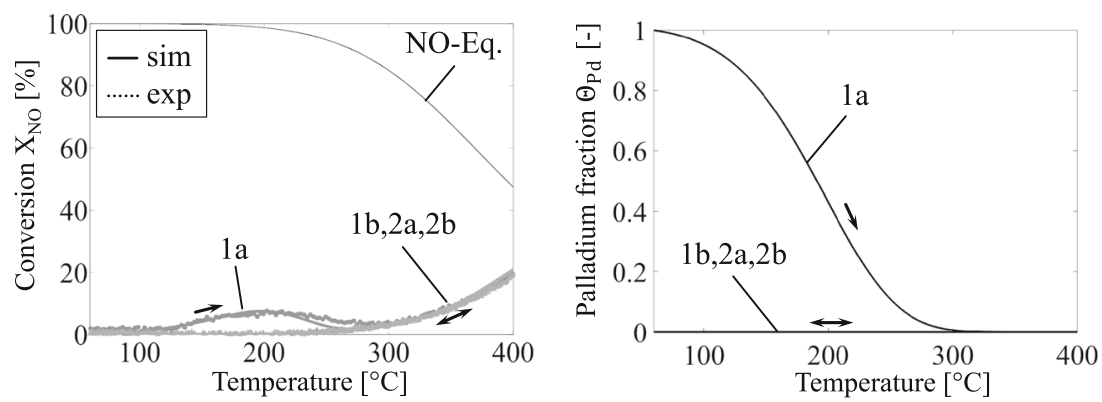

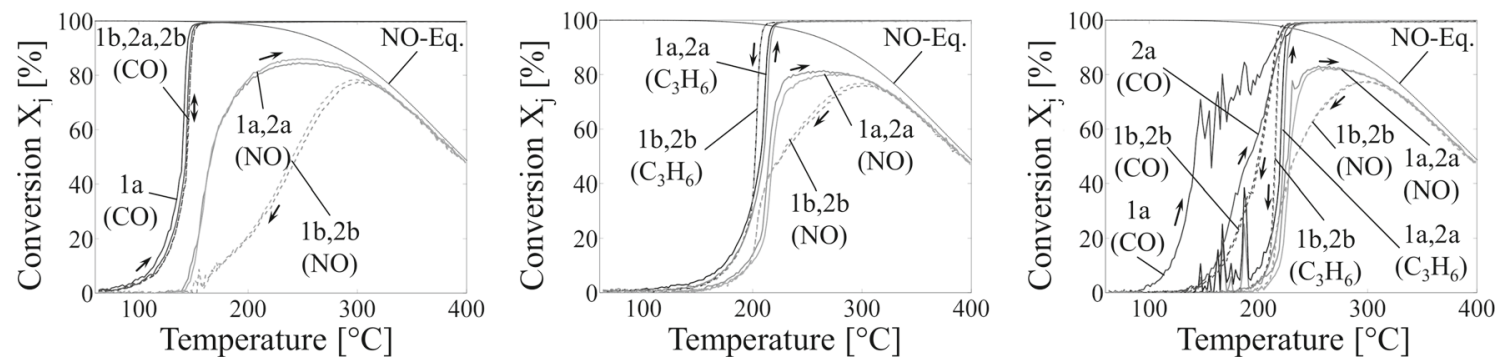

Fig. 7 Experimental results for $\mathrm{NO}(500 \mathrm{ppm})+\mathrm{CO}(800 \mathrm{ppm})($ left $), \mathrm{NO}(500 \mathrm{ppm})+\mathrm{C}_{3} \mathrm{H}_{6}(300 \mathrm{ppm})($ center $)$ and $\mathrm{NO}(500 \mathrm{ppm})+$ $\mathrm{CO}(800 \mathrm{ppm})+\mathrm{C}_{3} \mathrm{H}_{6}(300 \mathrm{ppm})$ on $\mathrm{Pt}$
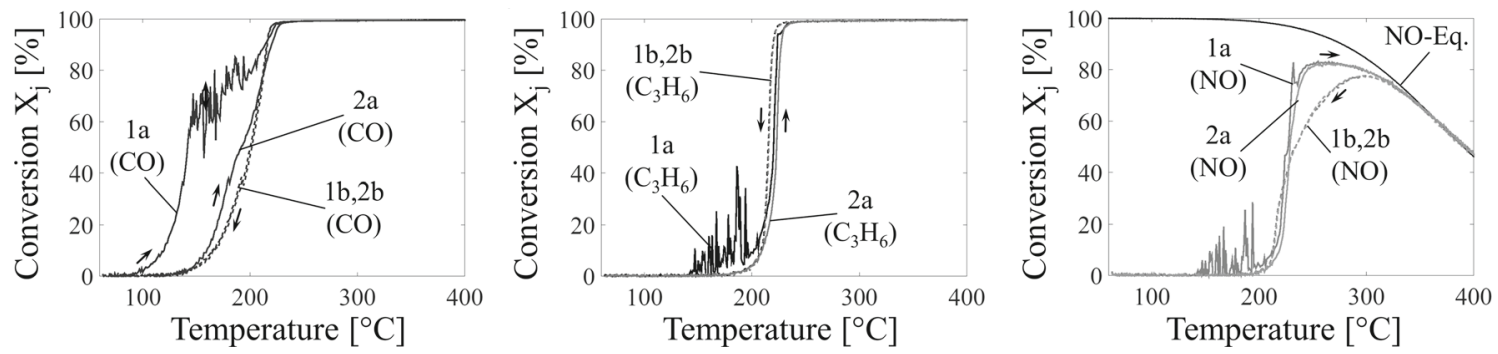

Fig. 8 Separate plots of the experimental results for $\mathrm{NO}(500 \mathrm{ppm})+\mathrm{CO}(800 \mathrm{ppm})+\mathrm{C}_{3} \mathrm{H}_{6}(300 \mathrm{ppm})$ on $\mathrm{Pt}$
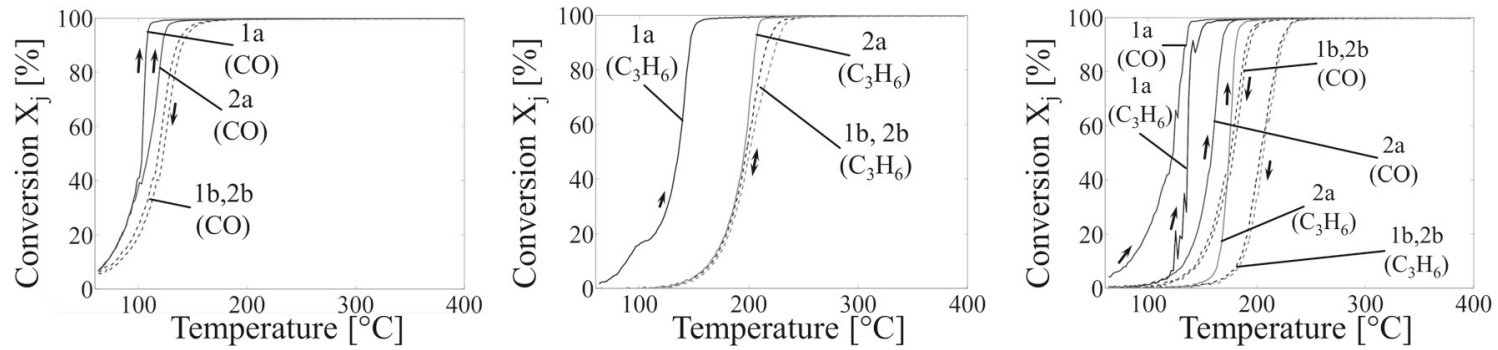

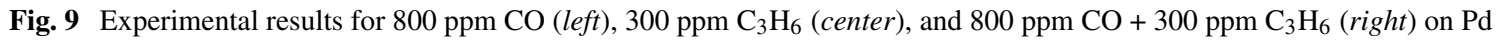
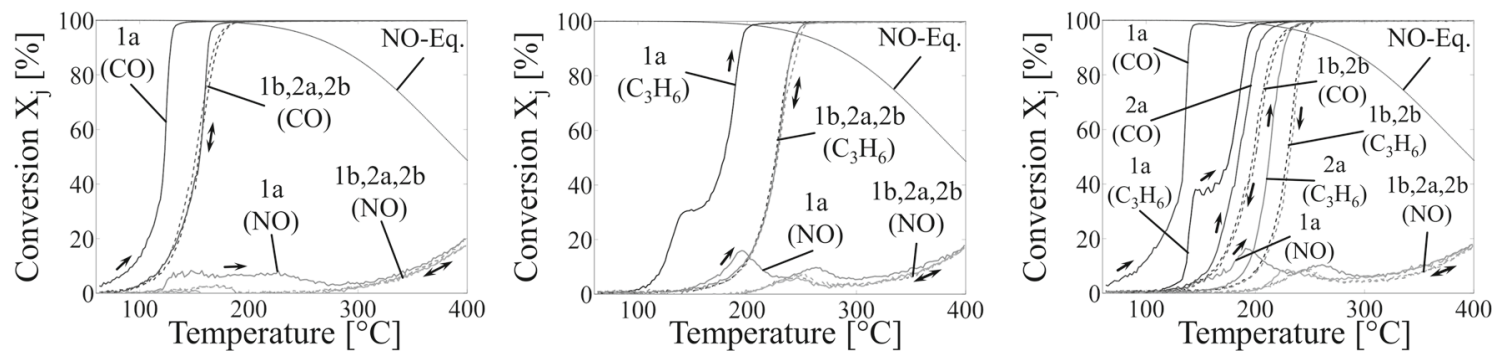

Fig. 10 Experimental results for $\mathrm{NO}(500 \mathrm{ppm})+\mathrm{CO}(800 \mathrm{ppm})($ left $), \mathrm{NO}(500 \mathrm{ppm})+\mathrm{C}_{3} \mathrm{H}_{6}(300 \mathrm{ppm})(\mathrm{center})$ and $\mathrm{NO}(500 \mathrm{ppm})+$ $\mathrm{CO}(800 \mathrm{ppm})+\mathrm{C}_{3} \mathrm{H}_{6}(300 \mathrm{ppm})$ on $\mathrm{Pd}$ 

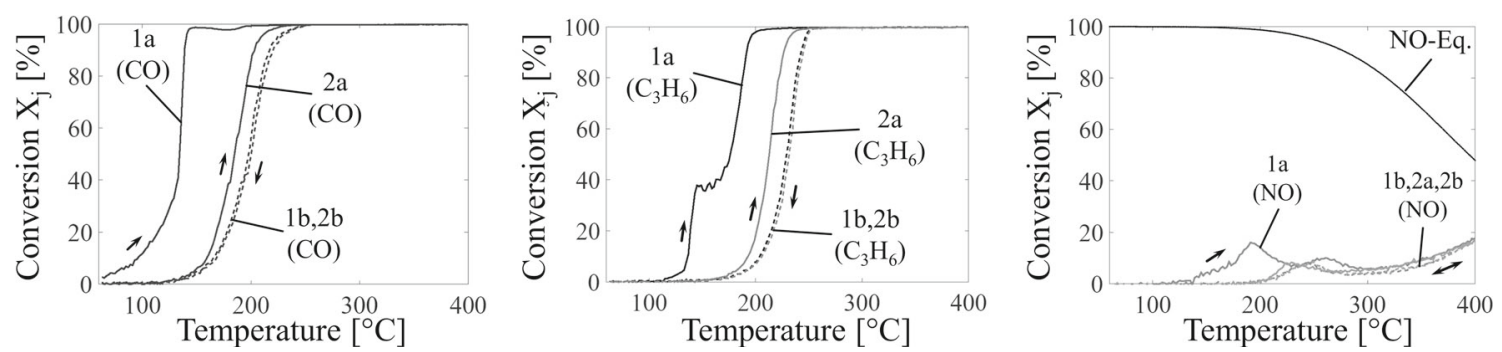

Fig. 11 Separate plots of the experimental results for $\mathrm{NO}(500 \mathrm{ppm})+\mathrm{CO}(800 \mathrm{ppm})+\mathrm{C}_{3} \mathrm{H}_{6}(300 \mathrm{ppm})$ on $\mathrm{Pd}$

When both $\mathrm{NO}$ and $\mathrm{C}_{3} \mathrm{H}_{6}$ are present in the feed, a different behavior can be observed (Fig. 7, center). The NO lightoff is now significantly impaired due to inhibition by propene, the first and second NO lightoff curves (1a, 2a) are nearly identical, again implying total reactivation of the catalyst through reduction of $\mathrm{PtO}$ by $\mathrm{NO}$ and $\mathrm{C}_{3} \mathrm{H}_{6}$, while $\mathrm{C}_{3} \mathrm{H}_{6}$ impairs the light-off of both oxidation reactions. This is in accord with M. Herrmann et al. who recently observed that the presence of $\mathrm{HC}$-decomposition intermediates can also reversibly impair the catalyst activity [12]. Since this deactivation is not connected to Pt oxidation/reduction, the first (1a) and second $\mathrm{C}_{3} \mathrm{H}_{6}$ light-off (2a) are identical. The fact that we do not observe a propene hysteresis in our experiments could mean that their hysteresis might have a thermal origin due to not completely isothermal reaction conditions.

Interestingly, if all three noxious substances $(\mathrm{NO}, \mathrm{CO}$, and $\mathrm{C}_{3} \mathrm{H}_{6}$ ) are present in the feed, severe oscillations in conversion can be reproducibly observed during first lightoff directly after reducing pretreatment (Fig. 7, right). For better readability, the conversion traces of each component are presented in separate plots in Fig. 8. Although this phenomenon has not been explained yet, it could indicate some kind of oscillating surface coverage effects of propene decomposition products. As mentioned above, Herrmann et al. observed a deactivation of Pt-DOCs due to HC intermediate formation on the surface which would favor the latter hypothesis [12].

\subsubsection{Palladium Catalyst}

A similar experimental study for mixtures of $\mathrm{NO}, \mathrm{CO}$, and propene was conducted with the Pd-only catalyst. The results are presented in Figs. 9, 10, and 11.
For CO-only oxidation (Fig. 9, left), a small inverse conversion hysteresis is observed which indicates that $\mathrm{CO}$ is also able to slightly reduce $\mathrm{PdO}$ at low temperatures under lean conditions. Thus, the reactivation may be described by an additional reaction as follows:

$\mathrm{CO}+\mathrm{PdO} \rightarrow \mathrm{CO}_{2}+\mathrm{Pd}$

When only NO is present in the feed, the first NO lightoff on reduced $\mathrm{Pd}, 1 \mathrm{a}(\mathrm{NO})$ exhibits a small conversion maximum at low temperature as seen in Fig. 6 (left). If $\mathrm{CO}$ is added (Fig. 10, left), a somewhat extended plateau compared to the NO-only measurement occurs. Different from Fig. 6, now a remaining, very small conversion maximum at low temperatures can be observed in subsequent cycles, indicating a small reduction of the catalyst by $\mathrm{CO}$ in the presence of NO. Hence, the respective rate equation should consider strong inhibition by NO.

Neither $\mathrm{C}_{3} \mathrm{H} 6$-only (Fig. 9, center) nor $\mathrm{C}_{3} \mathrm{H}_{6}$ in combination with NO (Fig. 10, center) is able to significantly reduce the catalyst, as can be seen by the correspondence of all ramps following the first ramp up. Interestingly, when all three noxious substances $\left(\mathrm{CO}, \mathrm{NO}\right.$, and $\left.\mathrm{C}_{3} \mathrm{H}_{6}\right)$ are present in the feed, the catalyst again shows a pronounced inverse hysteresis in $\mathrm{CO}$ and $\mathrm{C}_{3} \mathrm{H}_{6}$ conversion, which denotes some reactivation even though $\mathrm{NO}$ is present in the feed (Fig. 10 (right) and Fig. 11). It was however shown in Fig. 10 (left) that $\mathrm{PdO}$ reduction by $\mathrm{CO}$ is significantly inhibited by the presence of NO. Reaction (15) will not account for this behavior due to the strong inhibition by NO. Hence, further reaction steps need to be considered which account for some kind of reactivation which only occurs when $\mathrm{CO}, \mathrm{NO}$, and propene are present in the feed.
Fig. 12 Measured concentrations for $\mathrm{NO}(500 \mathrm{ppm})$ $+\mathrm{C}_{3} \mathrm{H}_{6}(300 \mathrm{ppm})$ on Pd-only (left) and on Pt-only (right) during first heat-up (1a)
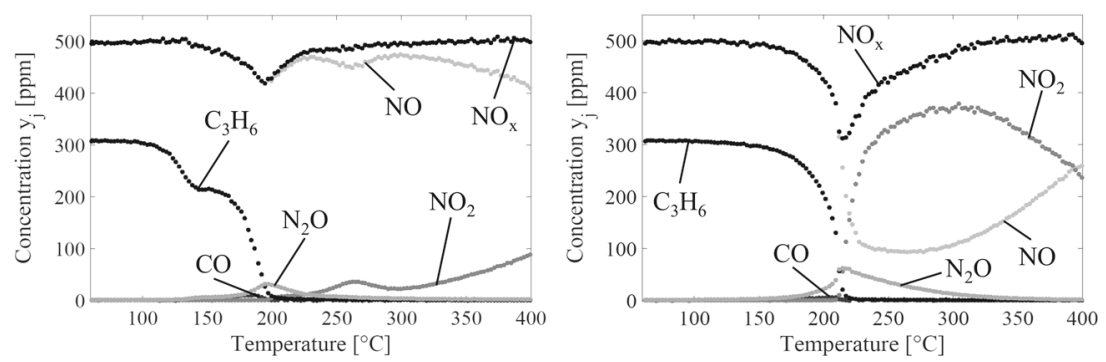
Interestingly, $\mathrm{N}_{2} \mathrm{O}$ formation has also been observed if $\mathrm{NO}$ and propene are present in the feed (Fig. 12). The $\mathrm{N}_{2} \mathrm{O}$ formation peak corresponds to a drop in $\mathrm{NO}^{x}$ concentration or a peak in $\mathrm{NO}$ conversion, which is more pronounced on $\mathrm{Pt}$ than on Pd (Fig. 10, center, right and Fig. 11, right). Hence, $\mathrm{NO}$ is obviously reduced to $\mathrm{N}_{2} \mathrm{O}$ at temperatures around $200{ }^{\circ} \mathrm{C}$ while with higher temperatures $\mathrm{NO}$ oxidation to $\mathrm{NO}_{2}$ prevails before thermal $\mathrm{NO}_{2}$ decomposition starts at still higher temperatures.

This formation of $\mathrm{N}_{2} \mathrm{O}$ seems to be the reason for the persistent maximum in NO conversion in Fig. 10 (center, right). During first heat up even, two maxima are observed. This causes the first maximum in NO conversion with a simultaneous drop of the $\mathrm{NO}^{x}$ value. Then, $\mathrm{PdO}$ formation starts lowering conversion once more. After complete oxidation, the conversion again rises during ongoing heating up.

Furthermore, during first propene light-of,f a pronounced saddle is observed for $\mathrm{C}_{3} \mathrm{H}_{6}$-only (Fig. 9 , center), $\mathrm{C}_{3} \mathrm{H}_{6}+\mathrm{NO}$ (Fig. 10, center), and $\mathrm{C}_{3} \mathrm{H}_{6}+\mathrm{CO}+\mathrm{NO}$ (Fig. 10, right). This behavior has also been reported by Khosravi [11]. Interestingly, if only $\mathrm{C}_{3} \mathrm{H}_{6}$ and $\mathrm{CO}$ are present in the feed (Fig. 9, right) during first ramp-up instead of a saddle, oscillations appear in the conversion curves of $\mathrm{CO}$ and propene, yet a lot less pronounced compared to those seen on Pt with all components (Fig. 7, right). Presently, no final explanation for these oscillations can be given. However, this phenomenon can be reproduced on different catalyst slices. A possible explanation here could also be the formation of $\mathrm{HC}$ intermediates as observed by Herrmann et al. on Pt catalysts [12].

\section{Conclusions}

In the current work, modifications to the existing noble metal oxidation model for NO on platinum catalysts $[2,4]$ have been presented. Hereby, good agreement between simulation and experimental results for different concentrations of NO has been achieved on Pt. Then the model was tested for a Pd-only catalyst, indicating that a transfer is in general possible.

Further experiments, with $\mathrm{CO}$ and/or propene added to the feed, were conducted on both platinum and palladium catalysts.

They show a spectrum of interesting phenomena, in particular if propene is present in the feed. Then $\mathrm{N}_{2} \mathrm{O}$ formation can occur at temperatures around $200{ }^{\circ} \mathrm{C}$ on $\mathrm{Pt}$ and to a smaller extent on Pd. Further experimental and modeling studies are required to elucidate how the different products of propene decomposition affect the NO conversion.

Acknowledgments Financial support by the Forschungsvereinigung Verbrennungskraftmaschinen (FVV e.V.) is gratefully acknowledged. Catalysts were provided by Umicore AG\&Co.KG.

\section{References}

1. Hauptmann, W., Votsmeier, M., Gieshoff, J., Drochner, A., Vogel, $\mathrm{H}$.: Inverse hysteresis during the NO oxidation on Pt under lean conditions. Appl. Catal. B Environ. 93, 22-29 (2009)

2. Hauff, K., Tuttlies, U., Eigenberger, G., Nieken, U.: Platinum oxide formation and reduction during $\mathrm{NO}$ oxidation on a diesel oxidation catalyst Experimental results. Appl. Catal. B Environ. 123-124, 107-116 (2012)

3. Nibbelke, R.H., Hoebink, J.H.B.J., Marins, G.B.: Kinetically induced multiplicity of steady states in integral catalytic reactors. Chem. Eng. Sci. 53(12), 2195-2210 (1998)

4. Hauff, K., Dubbe, H., Tuttlies, U., Eigenberger, G., Nieken, U.: Platinum oxide formation and reduction during NO oxidation on a diesel oxidation catalyst - Macrokinetic simulation. Appl. Catal. B Environ. 129, 273-281 (2013)

5. Linstrom, P., Mallard, W.: NIST Chemistry WebBook, NIST Standard Reference Database Number 69, National Institute of Standards and Technology, Gaithersburg, MD (http://webbook. nist.gov/chemistry)

6. Kirchner, T.: Experimentelle Untersuchungen und dynamische Simulation der Autoabgaskatalyse zur Verbesserung des Kaltstartverhaltens, 15-16. VDI-Verlag, University of Stuttgart (1997)

7. Neyestanaki, A.K., Klingstedt, F., Salmi, T., Murzin, D.Y.: Deactivation of postcombustion catalysts: a review. Fuel 83, 395-408 (2004)

8. Datye, A.K., Bravoa, J., Nelson, T.R., Atanasova, P., Lyubovskyb, M., Pfefferle, L.: Catalyst microstructure and methane oxidation reactivity during the $\mathrm{Pd}<->\mathrm{PdO}$ transformation on alumina supports. Appl. Catal. A Gen. 198, 179-196 (2000)

9. Cordi, E.M., Falcone, J.L.: Oxidation of volatile organic compounds on $\mathrm{Al}_{2} \mathrm{O}_{3}, \mathrm{Pd} / \mathrm{Al}_{2} \mathrm{O}_{3}$, and $\mathrm{PdO} / \mathrm{Al}_{2} \mathrm{O}_{3}$ Catalysts. J. Catal. 162, 104-117 (1996)

10. Zorn, K., Giorgio, S., Halwax, E., Henry, C.R., Grönbeck, H., Rupprechter, G.: $\mathrm{CO}$ oxidation on technological $\mathrm{Pd}-\mathrm{Al}_{2} \mathrm{O}_{3}$ catalysts: oxidation state and activity. J. Phys. Chem. C 115, 11031111 (2011)

11. Khosravi, M., Abedi, A., Hayes, R.E., Epling, W.S., Votsmeier, M.: Kinetic modelling of Pt and Pt:Pd diesel oxidation catalysts. Appl. Catal. B Environ. 154-155, 16-26 (2014)

12. Herrmann, M., Malmberg, S., Drochner, A., Vogel, H., Hayes, R., Votsmeier, M.: Activation and deactivation effects in diesel oxidation catalysts, emission control science \& technology, Accepted Manuscript 